\title{
THE INTEGRATED FAST SURVEY FOR THE RISK ASSESSMENT. A PROPOSAL FOR THE SAFEGUARDING OF THE MEDIEVAL CASTLES IN CENTRAL SICILY
}

\author{
A. Versaci ${ }^{1}$, L.R. Fauzìa ${ }^{1}$, M. Russo ${ }^{1}$, A. Cardaci ${ }^{2}, *$ \\ ${ }^{1}$ Faculty of Engineering and Architecture, University of Enna 'Kore', Italy - (antonella.versaci, luca.fauzia)@unikore.it, \\ archmichelerusso91@gmail.com \\ ${ }^{2}$ School of Engineering, University of Bergamo, Italy - alessio.cardaci@unibg.it
}

Commission II - WG II/8

KEY WORDS: Medieval Castles, Conservation, 3D Survey, Risks Assessment, Enna.

\begin{abstract}
:
The integrated survey carried out with both several technologies for the acquisition of metric data and information on materials and degradation pathologies, and procedures for data processing, offers the opportunity to be aware of the state of conservation of the built heritage following a procedure compatible with the protection and enhancement needs. The survey, if carried out in a quick way thanks to the recent videogrammetry software, ensures new and fruitful procedures for the cataloguing of monumental complexes for the purpose of risk mapping. Actually, the data captured by UAVs, together with the information obtained by the terrestrial measurement campaigns, if undertaken by the appropriate processes and the necessary skills, are an effective survey methodology for the criticality assessment of isolated architectural sites, like the strong medieval buildings which are still visible in the province of Enna, Sicily. Mostly abandoned and in the state of ruin architectures, which stand away from road infrastructure networks, they are often located in areas affected by depopulation, and risk to be forgotten and to disappear due to the inexorable passage of time. This work, through several case studies on relevant castles, wants to illustrate a project aimed at the knowledge and documentation of these important testimonies of the culture of the island, which only if suitably safeguarded and controlled would become the nodes of a widespread and sustainable tourist system, accessible to a wider public.
\end{abstract}

\section{INTRODUCTION}

Situated between the utmost point of the Italian peninsula and the northerly coast of Tunisia, Sicily has historically played a key role in the strategic, political and socio-economic context of the Mediterranean basin. By its fortunate geographical position, the mild climate, the beauty and productivity of its lands, it has always been considered a 'privileged area' and, therefore, constantly quarrelled among the many civilisations, which have controlled the political scene of the Mare Nostrum.

Dominations that, for centuries, have harassed its people contributing, however, to the constitution of that heterogeneous identity that is the most interesting characteristic of the Island.

Precisely the simplicity with which it became the prey of the various invaders has meant that fortresses, castles and towers were built: a heritage of a considerable extent in size and thickness (in Sicily there are about 400 specimens), which represents the tangible sign of the passage, the overlapping and the alternation of different cultures (Figure 1).

Most of these goods, important evidence in the Sicilian landscape, are today in a state of serious degradation and/or abandonment, damaged both by the inevitable passage of time and the lack of preservation activities, function and attendance.

Their understanding is often scanty, in spite of the studies carried out in the historical and architectural fields, both due to the shortage of archival sources and to other problems of a methodological nature such as, for example, the quasi-absence of stratigraphic analysis or chrono-typological atlas, at the regional level. Moreover, these structures are very often out to reach due to their impervious locations and to investigate because of their extent, size and spatial configuration (in general, rich in stratifications).

Difficulties that - despite the experiences carried out by the Regional administration (CRICD, 2001) and the Istituto Italiano dei Castelli - have to date prevented a complete, truthful and effective cataloguing, characterized by reliable and accurate metric and material surveys. Inquiries that should able to highlight, not only the metric dimensions and the geometric ratios but also the peculiar characteristics of the architectural vestiges in the context of the territory in which they are inserted (Gazzola, 1965).

'Documents' that would allow the analysis of the ancient construction techniques, the history and evolution of the defensive systems, their structural resistance and the collapse modalities following seismic activities. The main aim is to establish reliable comparisons and to define programs aimed at the viable conservation of places where history comes back to life through unique eyewitness accounts, yesterday as today.

In this sense, the authors of this paper have long been committed in a systematic investigation aimed at the documentation and inventory of these sites. The study - still in progress - intends to consolidate an operational practice based on the integration of innovative technologies for three-dimensional survey and mapping. Representation techniques capable of bringing out the morphological and material peculiarities and the state of conservation of the cultural assets and to promote a multidisciplinary approach in the study of a multi-layered heritage (Figure 2).

\footnotetext{
* Corresponding author
} 
The final purpose is to develop proposals for their conservation, enhancing and accessibility improvement.

Based on the activities already carried out in the Enna province an area rich in monuments often overlooked compared to the most famous coast - this paper intends to highlight the peculiar characteristics of a systematic programme aimed at the preservation and valorisation of fortified structures, mostly in a state of disrepair or ruin.

\section{THE MEDIEVAL CASTLES IN SICILY: A RICH HERITAGE TO BE DISCOVERED}

The militarization of Sicily takes shape in the late Byzantine period, in response to the long Muslim invasion, so altering the late antique facies characterized by a considerable fragmentation of the town.

The Sicilian landscape is thus affected by an early and extensive phenomenon of fortification due to the state of conflict that Arab incursions had generated around the Mediterranean Sea (Maurici, 1992). Several sea outposts are fortified and equipped with sighting towers, to defend the authority.

For the first time, there is a clear distinction between power and subjects: the fortified village is separated by the governmental fortress, which, more and more often, raises in the highest and most inaccessible part of the city (Giuffrè, 1980).

The Norman conquest of Sicily initiates an era of great violence and as many destructions: the few sources of this age describe a country strewn with ruins, where the most beautiful constructions of the Islamic age had been demolished (Cresti, 2007).

The Byzantine fortification underwent a definitive change in this period, simultaneously playing the defensive and residential role. The new Norman fortification, the castellum, takes its place in the various pre-existing castras and becomes the symbol of the power of the king and the feudal lord who represents it.

In the absence of typical Sicilian architecture, the castles built during this period refer to the models of Northwestern Europe from where the Normans came (Brocato, 1986). In Sicily, however, castles are not merely the symbol of feudal power but also of the Crown. Frederick II of Swabia to repress the advance of feudalism destroys a great portion of them. He then substitutes the ancient castles with 'royal' ones, largest and fortified, and populates cities and countryside with new structures mainly having functions of pleasure and amusement.

In the years following the rebellion of 1232 and the battle of Cortenuova (1237), the network of castles is redefined. Going from Trapani to Syracuse, from Termini Imerese to Augusta they constituted the strategic elements of a vast defensive system. Focal points are, on the one hand, the Maniace castle of Syracuse, to defend the Eastern coast of Sicily, and on the other hand, that of Lombardy in Enna, the ancient Castrogiovanni, which bars the line of Salso River.

In the articulated process of the Sicilian settlement that develops between the 13th and the 15th centuries, we assist in the 14th century to an important accentuation of both the territorial transformation and the built-up areas' dynamics. The war has a significant influence in this sense: the Angevin revenge between 1313 and 1348 is particularly devastating as well as the civil war that, starting from 1340, opposes the great feudal dynasties. The castle in the demiurgic ambition of a general 'encastellation',

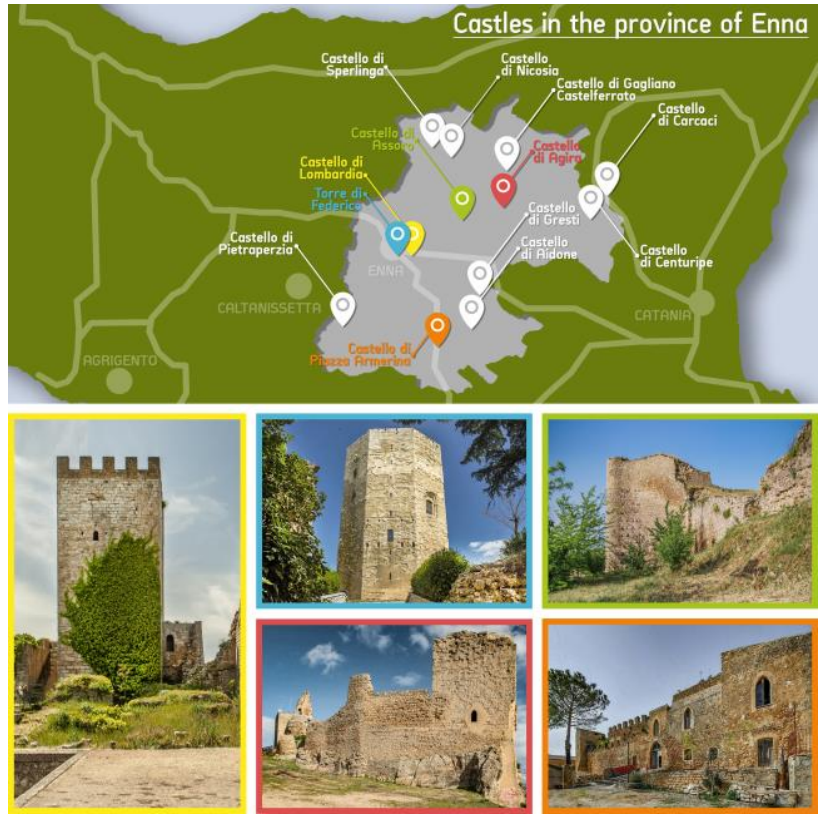

Figure 1. Some castles and towers in the province of Enna.

plays a central role in the military strategy of Frederick III and constitutes the strong point of his defence system against the Angevin kings (Charles II and then Robert). It is probably due to him the construction of the octagonal tower di Federico in Enna, whose denomination today is much more attributed to Frederick II Hohenstaufen, the Holy Roman Emperor (Bresc, Maurici, 2009). Starting from the mid-14th century, during the war that opposes the great baronial families, dozens and dozens of baronial castles, among large, small and tiny are erected and enrich the already vast existing architectural heritage.

In the pacified Sicily of the 15th century, the growing necessities for restoration and maintenance work lead to necessary selection processes. In particular, the castles of the hinterland progressively lose their military importance and are frequently reused as prisons.

Therefore, a period of progressive decadence, abortion or premature obsolescence starts, unfortunately never interrupted. Today in the province of Enna, it is possible to enumerate twentytwo castles and towers: monuments that require, in large part, urgent operations of safeguarding and, above all, new knowledge activities.

\section{INNOVATIVE METHODS FOR THE KNOWLEDGE AND THE DOCUMENTATION OF FORTIFIED ARCHITECTURE}

The knowledge of historic buildings requires a multidisciplinary methodology, able to integrate the technical capabilities of the engineering field with the humanistic approach of the historical sciences. It is a preliminary activity to any conservation intervention, which asks for sensitivity, understanding, critical spirit and experience. A step that is not possible to delegate to the exclusive use of digital sensors and which requires specific and targeted skills that only the connoisseur of architecture possesses (Fallavolita, Ugolini, 2017).

The research activities undertaken have been based on these assumptions; they have merged the most accurate geometric survey with the critical analyses, also supported by diagnostic 
studies to produce thematic maps related to chronological events, materials, pathologies, etc.

More specifically, an integrated surveying methodology, which applied both several technologies for the attainment of both metric and qualitative information on construction materials and decay phenomena, and for the data processing, has been considered as a founding element of the cognitive campaigns carried out or still in progress.

The different instruments employed have been chosen based on the needs that have arisen from time to time - in terms of site accessibility, size, articulation, conservation state of the artefacts and on their ability to adequately support the process of awareness of the built heritage, for its protection and valorisation (Versaci, Cardaci, 2011).

The traditional survey supported by the use of terrestrial active (3D laser scanners) and passive sensors (digital Photogrammetry) has been, where necessary, completed by the information taken by small drones, to ensure three-dimensional models of high geometric reliability and high chromatic quality (Figure 3 ).

The combination of several measurement techniques, together with the adequate homogenization of data processing software, has allowed the rapid development of virtual models of the architectural objects and their environments (Figure 4). An investigation praxis, which complies with the criticalities' mapping of heritage in a state of ruin, such as some of those considered: in particular, the castles of Agira, Assoro and Piazza Armerina.

Over the last decade, the combined use of several survey techniques appeared very laborious, but recently, thanks to more flexible and efficient platforms, the sharing of multiple models in the single milieu - points and/or polygonal meshes - has become a competitive technology, able to provide full digital models. What is not visible from the 'ground' can be snapped from an 'aerial' camera placed on a drone.

However, as already mentioned, the activity planning and the 'personal' contact with the monument (the so-called 'live drawing') remain the indispensable primary steps to carry out the work in a conscious way, well focused on the objective to be achieved. The drafting of sketches and functional diagrams on the volumetric articulation and surfaces, the examination and recognition of the construction techniques, the materials and their conditions, always has fundamental importance for the full understanding of the architectural objects.

Another element to take into consideration is the drafting of a specific survey program that must adapt to the specific characteristics of the case study. In addition to having to orientate in the choice of the tools to be used among the many made available by today's technology (appropriately evaluating pros and cons), it is fundamental to define, preliminarily and with extreme care, activity planning consistent with the characteristics of the site. The survey is, therefore, set up after a scrupulous inspection of the places, aimed at assessing the most appropriate instruments and the most suitable operating practices for achieving the purpose. The acquisition campaign is the implementation of a program designed and simulated in advance that allows operating quickly and effectively, limiting errors and improving the quantity and quality of the information acquired. A modest initial investment allows both obtaining better results, to reduce acquisition times, and to simplify and facilitate subsequent post-processing operations.

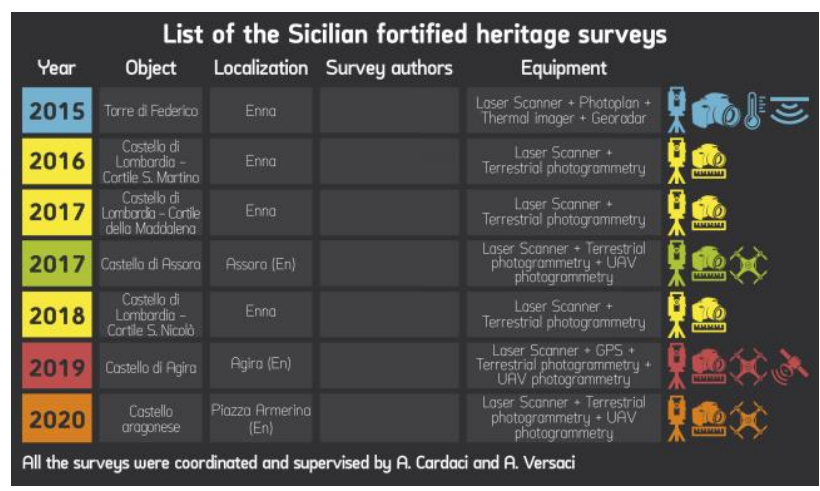

Figure 2. Chronological list of the fortified heritage surveys carried out in the province of Enna with the description of the instruments used.

The Lombardy castle in Enna, but even more the castle of Assoro presented only a few visible parts and insisted on large archaeological deposit, in many parts not excavated. In this second specific case, the activities were designed to detect both the position and the metric characteristics of the existing finds to catalogue (by the drafting of datasheets with hypertexts containing descriptive parts, detailed drawings and adequate photographic documentation). In addition to the ruins of the walls of the castle, in the same area we can find traces of other bastions, fragments of columns, water channelling systems and underground spaces, including the remains of a cave oratory.

The vast extension of the complex has imposed a choice on the resolution and metric accuracy resulting from a fair compromise between costs (time and resources) and quality of results. A single high-resolution model able to include every detail of the castle area would have required many hours for data acquisition and processing, to finally obtain a database however hard to consult; in contrast, a low-resolution model, although easier to query, would have provided little detailed information.

A multi-scale system was considered the best solution (Federman et al., 2017). It was composed by several geo-referenced models in a single virtual environment: some very accurate because reconstructed by 3D laser scanner acquisitions, terrestrial photogrammetry and aerial images at low altitude, and others less precise as acquired by low-cost 3D systems and amateur easy-fly drones. The virtual model was used to obtain orthographic projections of both façades (at scale 1:50) and plans (at scale $1: 100)$ necessary for the preliminary analyses for the conservation project of the urban park.

In other situations, such as for Agira and Piazza Armerina castles, it was decided to employ the drone to survey the entire areas: in the first case, to acquire the morphology of the rock mass on which the castle is situated and in the second case to appreciate the relationships with the urban environment. Overflights were conducted according to a flight plan duly established and were based on both the characteristics of the vehicle and the optical system installed in it. In particular, to produce multiscale models, different altitudes were chosen lower near the ruins for better restitution of the architectures, higher for the planimetric and the territorial/urban contexts reconstruction.

In aerial photogrammetry, much more than in the terrestrial one, it is necessary to preliminary draft a project to which strictly adhere. The lower quality of the images (swiftly captured from an instrument in movement) and the reduced times for the execution of the shots (dictated by the duration of the batteries) 

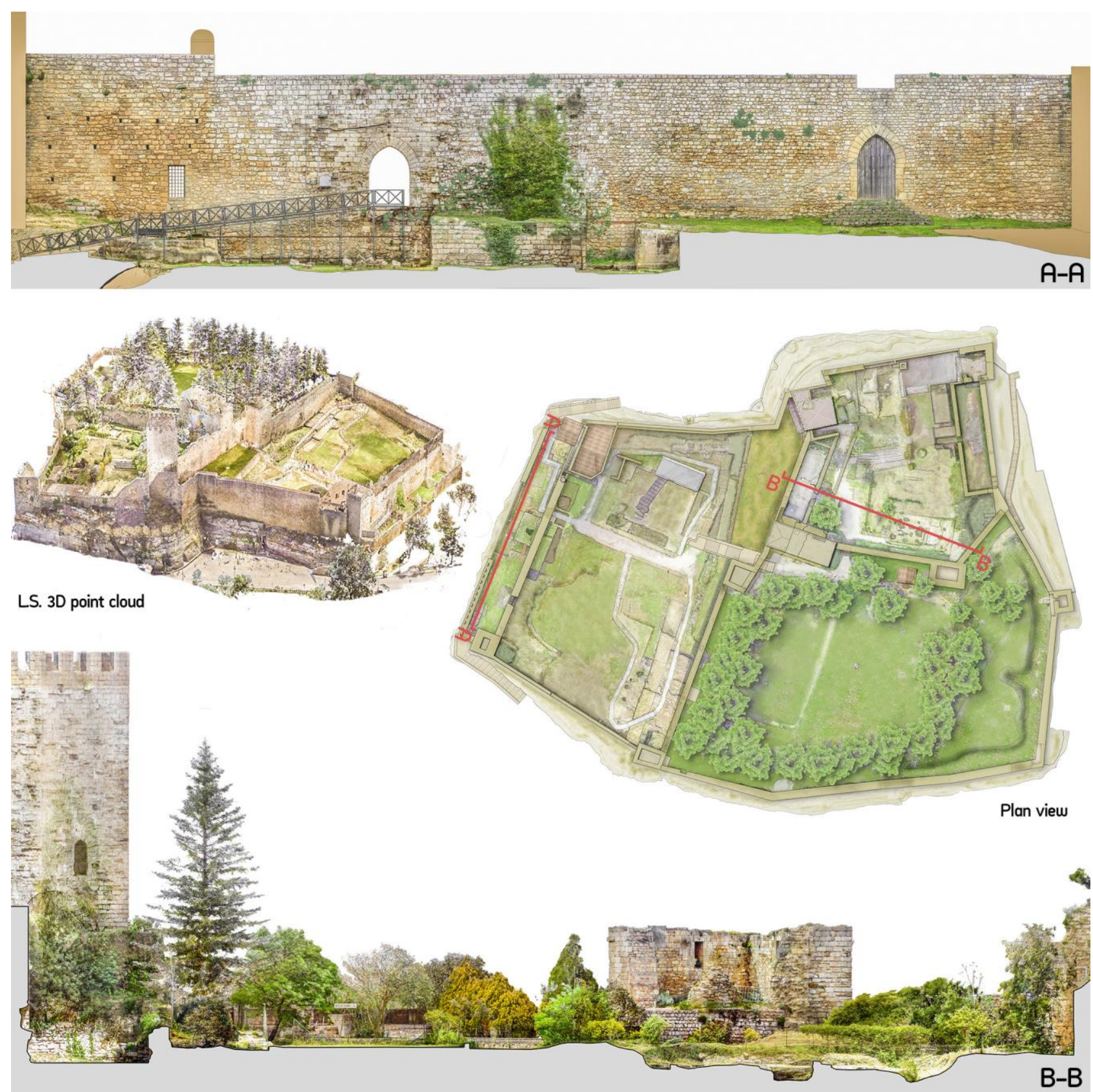

Figure 3. The Lombardy castle in Enna: laser scanning data and outputs.

does not allow, in fact, any approximation and/or improvisation. It is mandatory to be wary of inexperienced pilots and operators. The new automated drones and data processing software can provide accurate results only if processed with knowledge and professionalism.

In general, the survey from a drone appears very useful to obtain a planimetric view of monumental complexes in their environmental context, to access the steepest parts, to acquire, in particular, the wall crests. In the case studies undertaken, JPGtype images were used to complete the architecture models and full HD videos for the environmental areas. To integrate air and land models, catches must be made with method and care. The cameras mounted on small drones do not allow the same adjustments which are possible with a reflex and have, besides, a low resolution and high noise. It is therefore important to set a very low flight altitude and fly close to the walls to have a high
GSD and a frame overlap greater than $60-70 \%$ (Federman et al., 2018). The shots need to be taken both with the camera placed horizontally (for the façades) and vertically (for the wall crests). Instead, an automatic flight can be selected for surveying the whole area, preferring videogrammetry to the individual shots.

The metric accuracy of the photogrammetric survey was verified by overlapping the $3 \mathrm{D}$ laser scanner survey thanks to uniquely recognizable targets; the latter were used both to orient and resize the photogrammetric models (GCP), and for the quality control of the rendering (QCP). The construction of a global model was possible thanks to the use of the 3DFlow ${ }^{\circledR}$ Zephyr platform which allowed to import the photogrammetric models and to superimpose them on the point cloud of the 3D laser scanner. From the model orthographic projections, useful to support the characterization of the material, as well as stratigraphic and decay mapping, were extracted. 

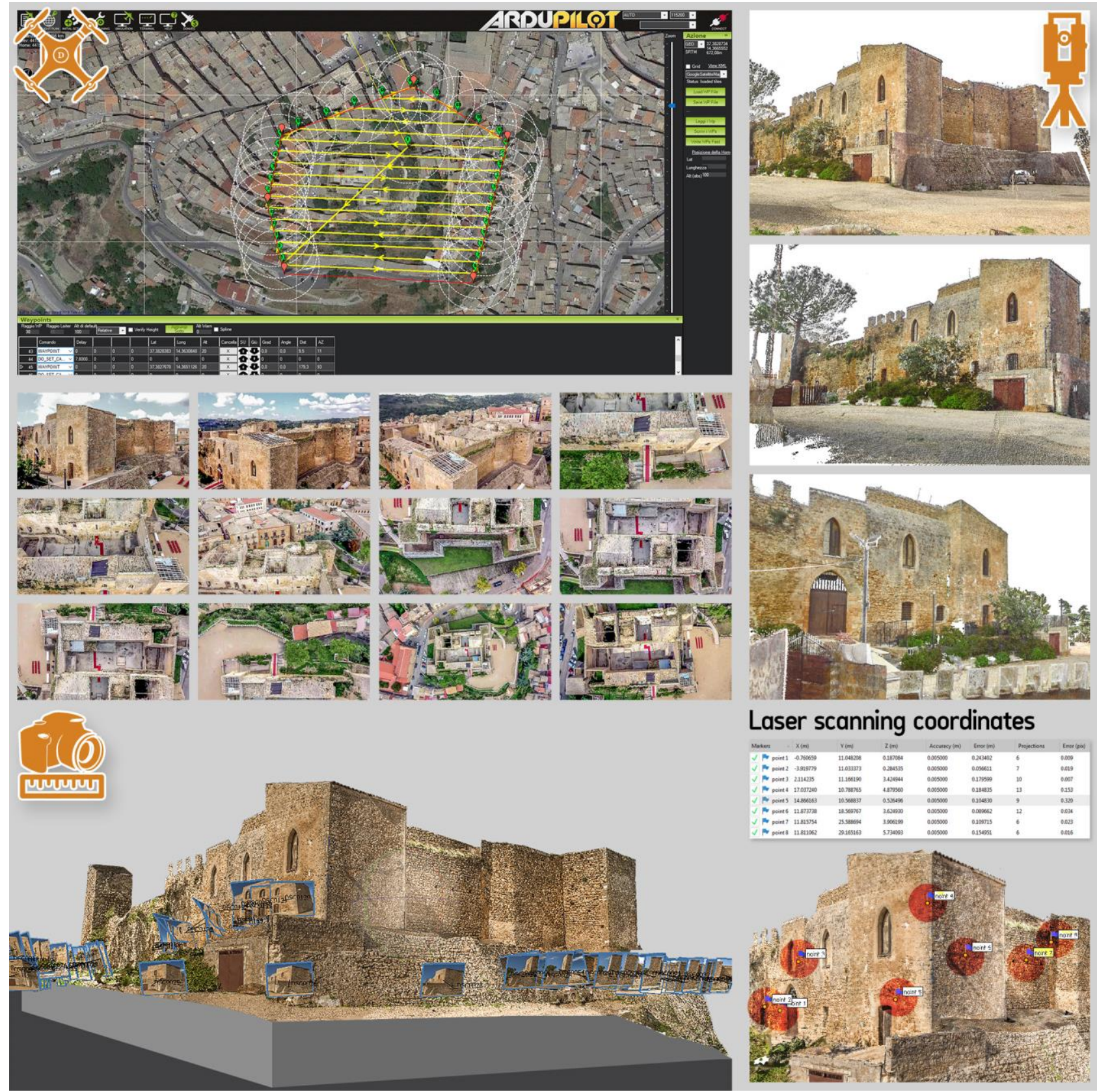

\section{Laser scanning coordinates}

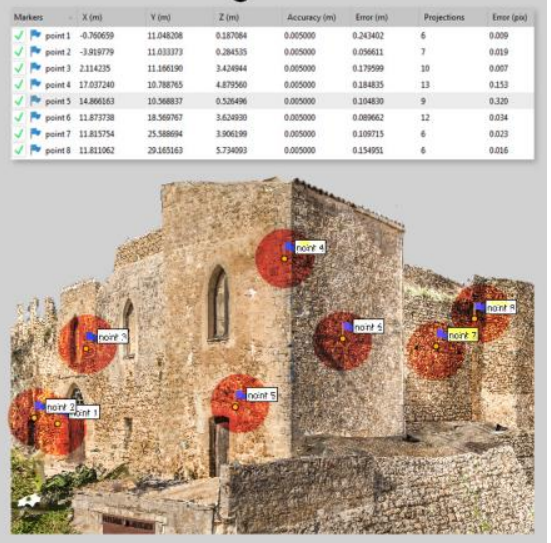

Figure 4. The castle of Piazza Armerina: integrated survey.

\section{THE KNOWLEDGE PROCESS IN SUPPORT OF CONSERVATION AND ENHANCEMENT PROJECT}

The surveys and the studies of historical sources carried out led to the collection of a vast archive of information on the fortified heritage examined. Starting from these data, elaborate graphs of characterization of the building typologies have been produced, as well as representations of the state of decay of the surfaces with the indication of the conservation hypotheses. Project proposals related to the reuse of the sites - attentive to the requests for accessibility, aesthetic and material compatibility of the grafts and based on the principles of recognizability and minimal intervention were established.

As already mentioned Sicily suffers from the absence of an organic and structured study of the historical masonries widespread in its territory. This lack has led to many difficulties in defining an operating practice and a unique lexicon able to appreciate the different constructive techniques found in the case studies examined; an activity that constitutes a fundamental prerequisite for the stratigraphic analyses of any architectural artefact before its restoration (Parenti, 1998). To standardize the wall masonries which characterise the analyzed castles, we then proceeded to compare the textures based on the type of stone used, the size of the ashlars, their distribution, the types of reinforcements (if any), the mortars employed (Alagna, 2008)

Through this comparative study, it was possible to recognize and register the recurring typologies of walls; to identify them in the elevations by associating a specific code and standardizing their graphic representation with the assignment of different colours to define the shape and extent of the typologically uniform wall surfaces (Figure 5).

For the stratigraphic study of the walls, a multi-disciplinary approach was used which involved medieval archaeologists. In this context, it is essential to adopt a univocal and shareable data 


\section{Castello di Assoro}
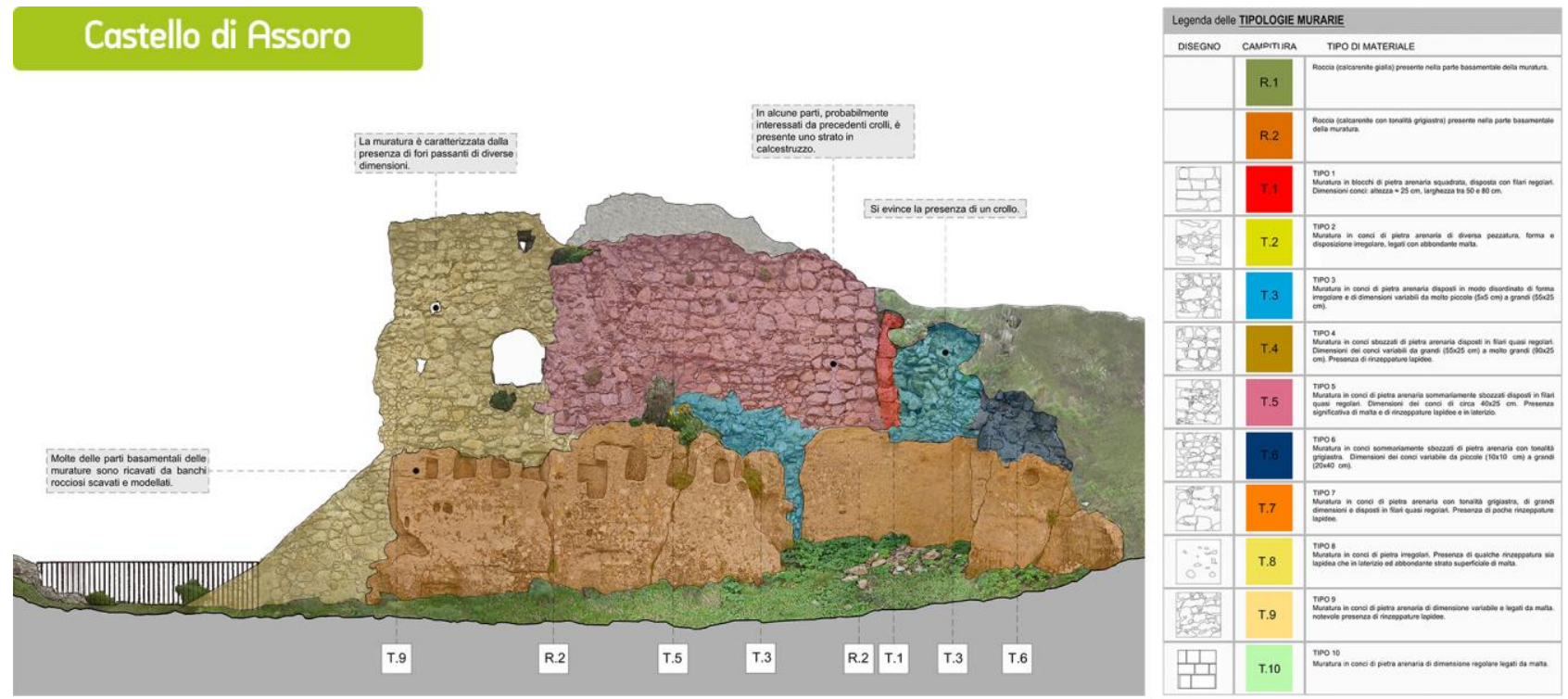

\section{Castello di Agira}
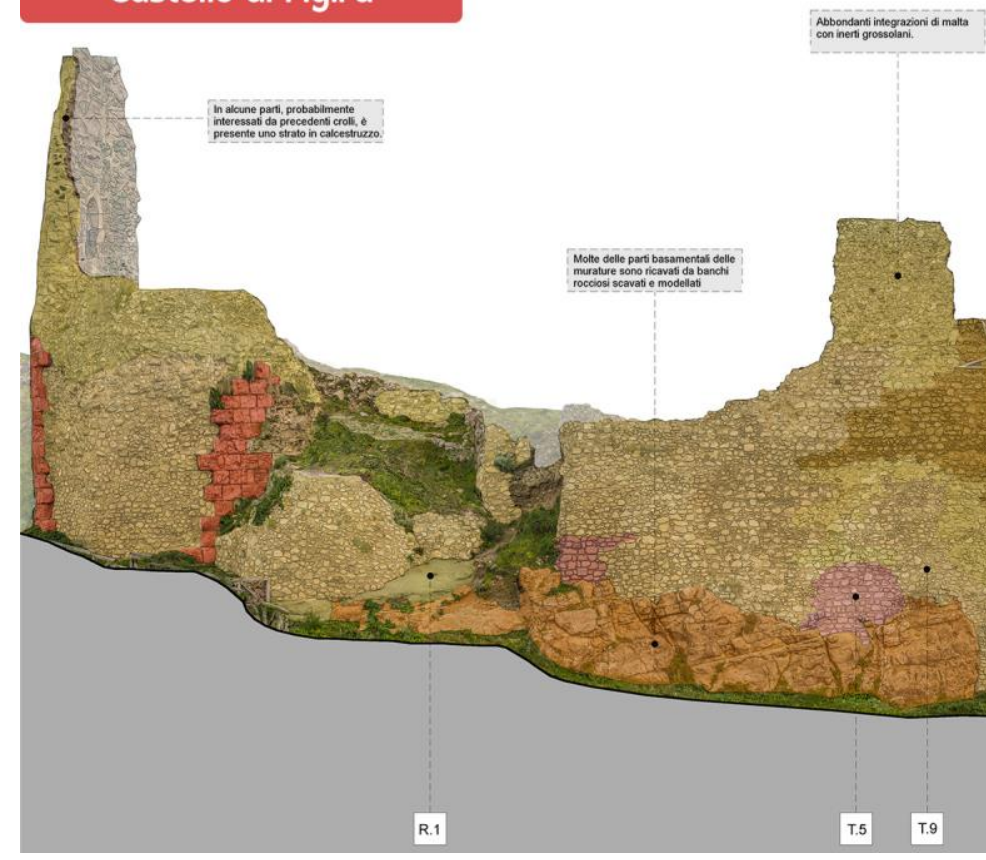

Figure 5. Characterization of masonry typologies in the castles of Assoro (above) and Agira (below).

collection methodology, which can make effective the collaboration of professionals with a different background, but who must necessarily confront themselves on exhaustive and understandable documentation not only from an archaeological point of view but also for the requirement of the restorers. This latter can cope with the design choices, dictated by conservative instances, only based on a shared stratigraphic analysis that manages to define and date, at least in a relative way, the transformations that took place in the architectural artefact also in a state of ruin.

In particular, as part of the studies on the surviving architectural artefacts of the castle of Assoro, the recognition of the wall typologies was also supported by sampling and filing of the mortars (Figure 6).

Also in this procedure, the collection of data on mortars needed to take place with both a unique methodology and language recognized in the archaeological field. For this purpose, reference was made to cataloguing sheets of mortars employed in the field of architectural archaeology (Arrighetti, 2012), so facilitating the collaboration with collegues specialized in the stratigraphic reading of masonry structures. Thanks to the autoptic analysis of the mortars, ten types have been identified; for each of them, a sample was taken and a data sheet was produced to briefly describe their physical and chemical characteristics. In other cases, the information obtained from the survey, the study and critical understanding of the remains have been integrated by diagnostic campaigns supported by the use of active and passive sensor: instruments capable of obtaining information not visible to the human eye (Musso, 2004).

Thermographic images of the external façades in square stones were acquired at the tower of Federico in Enna that, suitably superimposed on their architectural representations, have provided important support for the understanding of the portions of the wall reinstated during recent restoration interventions, not enough supported by documentation. 

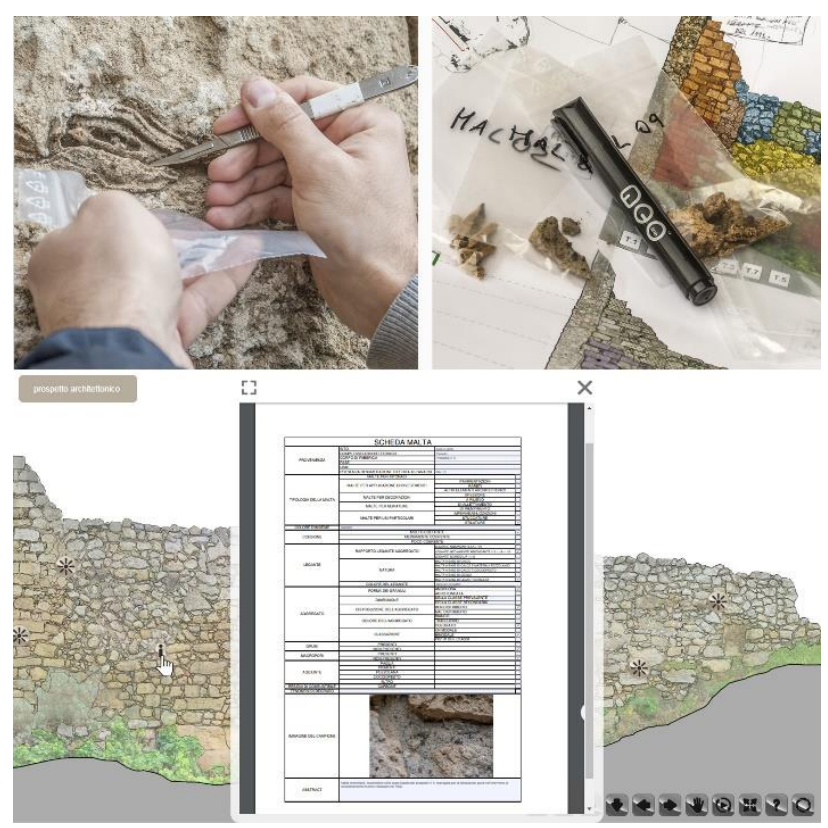

Figure 6. The mortars analysis undertaken in the castle of Assoro: collection, cataloguing and identification.

The many unresolved questions about Federico's tower, due to the lack of historical documentary sources, require appropriate excavation campaign primarily focused on the area between the tower and the external wall remains.

On the other hand, as part of the activities undertaken on this site, the research was integrated by georadar investigation of the area surrounding the tower and by endoscopic inspections of the walls. These non-destructive investigations have provided evidence of some discontinuities present in the subsoil and inside the walls, highlighting the need for further archaeological investigations.

The cognitive processes undertaken in the various case studies relating to the Sicilian fortified heritage have the ultimate goal of defining conservation, use and enhancement proposals compatible with the historical value of these goods and respectful of the surviving traces (Figure 7). These elements are of fundamental testimonial importance (Varagnoli, 2005).

For this reason, the design proposals formulated in the different sites, although presenting functional characteristics and needs that respond to the peculiarities of each place, are united by the clear desire to make this heritage more accessible, to facilitate the reading of the ruins and to introduce proposals of refunctionalization. New functions compatible with the preexistences and which can guarantee a cultural attraction capable of making the ancient castles more lived by visitors and by the local communities themselves.
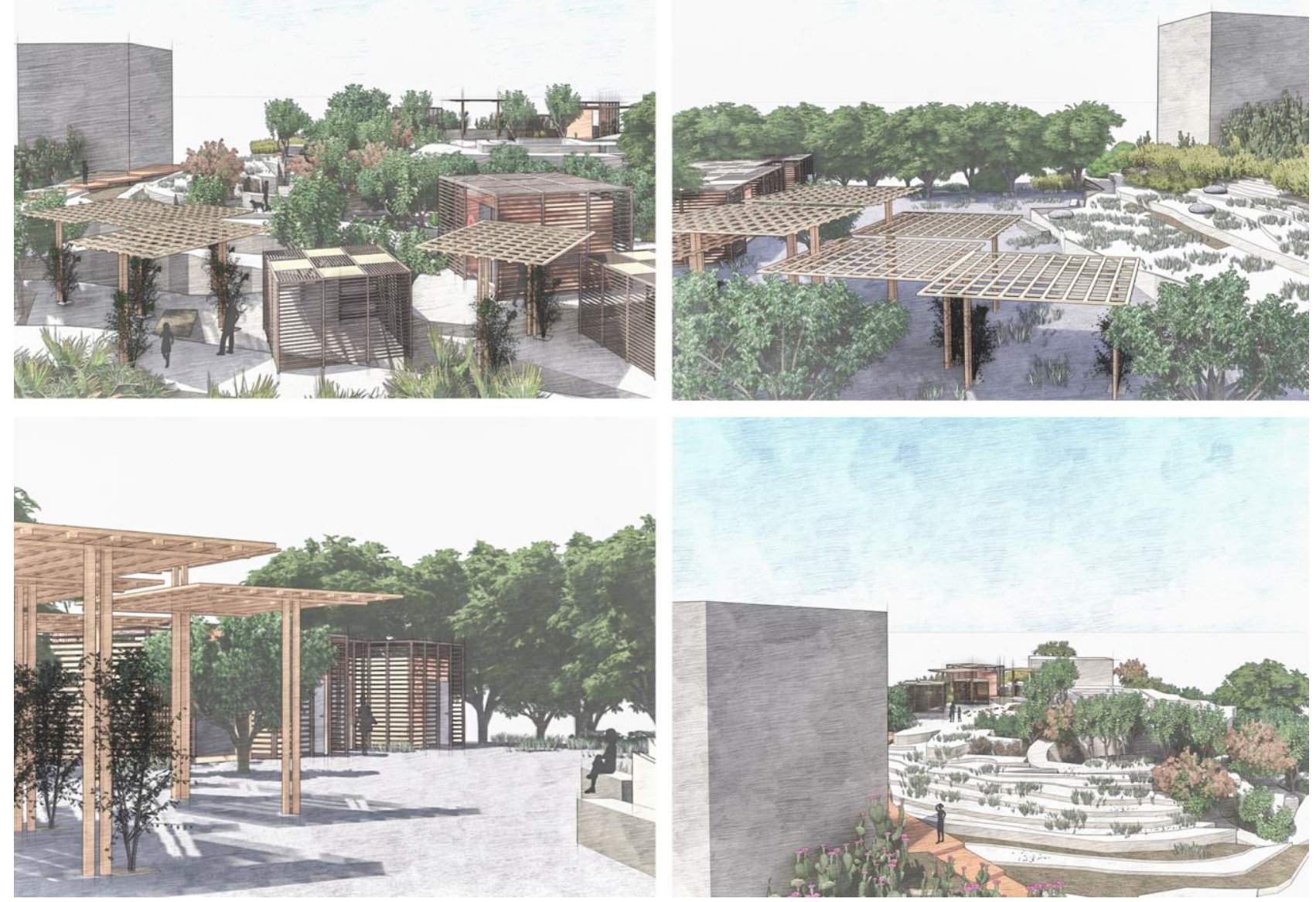

Figure 7. Site enhancement proposals for the castle of Agira. 


\section{CONCLUSIONS}

The integrated survey carried out both with different technologies for the acquisition of metric data, materials and degradation pathologies and with different procedures for data processing, offers the opportunity to be aware of the state of conservation of the built heritage, following a procedure compatible with the protection and enhancement needs. The inventory and study of these architectural artefacts are, in fact, still today based on direct investigations, photographic investigations and, if existing, on old architectural surveys often incomplete and not very accurate that misrepresent the actual state of the goods.

The aerial shots, now possible thanks to the use of small drones, if integrated with more accurate measurements performed with active (3D laser scanning) and passive sensors (digital photogrammetry), can return three-dimensional models of high geometric reliability and elevated chromatic quality. The data captured by UAVs, together with the information obtained by the terrestrial measurement campaigns, if treated with the appropriate processes and the necessary skills, are an effective survey methodology for the evaluation of the criticality of isolated architectural sites frequently located in non-urban areas - like the strong medieval buildings which are still visible in Central Sicily. Almost derelict architectures, which, in general, stand away from road infrastructure networks. Located in areas affected by depopulation, they risk to be forgotten and to disappear, due to the inexorable passage of time.

The case studies here presented intended to illustrate a project aimed at the knowledge and documentation of these important testimonies of the culture of the island. Fortresses that are identifying elements of the territory as well as highly recognized and recognizable architectures that only if suitably safeguarded and controlled would become the nodes of a widespread and sustainable tourist system accessible to a wider public.

\section{REFERENCES}

Alagna, A., 2008. Stratigrafia per il restauro architettonico. Il metodo dell'analisi stratigrafica delle superfici murarie per la conoscenza e la conservazione del costruito storico. Roma, Aracne.

Arrighetti, A., 2012. Archeologia dell'architettura e ricognizione di superficie nel comune di Sesto Fiorentino (FI). Archeologia dell'architettura, XVII, 173-190.

Bresc, H., Maurici, F., 2009. I castelli demaniali della Sicilia (secoli XIII-XV). Panero F., Pinto G. (eds.), Castelli e fortezze nelle città italiane e nei centri minori italiani (secoli XIII-XV). Cherasco, Centro Internazionale di Ricerca sui Beni Culturali.

Brocato, D., 1986. I castelli della provincia di Enna. Siracusa, Ediprint.

Cresti, F., 2007. Città, territorio, popolazione nella Sicilia musulmana. Un tentativo di lettura di un'eredità controversa. Mediterranea Ricerche storiche, IV, 21-46.

CRICD - Centro regionale per l'inventario, la catalogazione e la documentazione grafica, fotografica, aerofotografica, fotogrammetrica e audiovisiva dei beni culturali e ambientali (ed.) 2001. Castelli medievali di Sicilia: guida agli itinerari castellani dell'isola. Palermo; Regione siciliana, Assessorato dei beni culturali ambientali e della pubblica istruzione.
Fallavollita, F., Ugolini, A., 2017. New methodologies for the documentation of fortified architecture in the state of ruins. ISPRS - International Archives of the Photogrammetry, Remote Sensing and Spatial Information Sciences. XLII-5/W1: 411-418.

Federman A. Santana Quintero M., Kretz S., Gregg J., Lengies M., Ouimet C., Laliberte J. 2017. UAV photogrammetric workflows: a best practice guideline. In ISPRS - International Archives of the Photogrammetry, Remote Sensing and Spatial Information Sciences, XLII-2/W5: 237-244.

Federman, A., Shrestha, S., Quintero, M., Mezzino, D., Gregg, J., Kretz, S. and Ouimet, C., 2018. Unmanned Aerial Vehicles (UAV) Photogrammetry in the Conservation of Historic Places: Carleton Immersive Media Studio Case Studies. Drones 2(2): 18.

Gazzola, P., 1965. Un patrimonio storico da salvare: i castelli. Castellum, 1, 7-16.

Giuffrè, M., 1980. Castelli e luoghi forti di Sicilia. Palermo, Cavallotto.

Maurici, F., 1992. Castelli medievali in Sicilia. Dai bizantini ai normanni. Palermo: Sellerio editore.

Musso, S.F., 2004. Recupero e restauro degli edifici storici. Guida pratica al rilievo e alla diagnostica. Roma, EPC libri.

Parenti, R., 1998, Registrazioni delle tecniche costruttive. De Marchi, M., Mailland, F., Zavaglia, A. (eds.), Lo spessore storico in architettura tra conservazione, restauro, distruzione. Milano: Regione Lombardia, Servizio Musei e Beni Culturali.

Versaci, A., Cardaci, A., 2011. Integrated survey techniques for the study and the restoration of cultural heritage: some case studies in Enna (Italy). IX International Forum "Le Vie dei Mercanti": S.A.V.E. Heritage Safeguard of Architectural, Visual, Environmental Heritage. Napoli, La scuola di Pitagora.

Varagnoli, C. (ed.), 2005. Conservare il passato. Metodi ed esperienze di protezione e restauro dei siti archeologici. Roma, Gangemi Editore. 